\title{
Feasibility of Fuel Synthesized from Solid Plastic Wastage
}

\author{
Prafull Tiwari, Kunal Jain, Kushagra Dubey, Mohammed Ali, Manish Thakur
}

\begin{abstract}
The growing human population is increasing the consumption of fuels day by day in order to fulfill the requirement of human activities. This demand is also resulted in hiking the fuel prices. Also, the electric vehicles have not so far able to impress the market since their prices are comparatively higher than their counterparts that is motor fuel vehicles and hence isn't the first choice for people. Also, the rapid growing human population has introduced other problems like pollution and waste produced by humans from different activities like construction, household, industrial, etc. One of the most common waste produced in a large quantity is plastic which is nonbiodegradable. Existing way to deal with the plastic is to recycle it which itself produces toxic wastes. As an alternative pyrolysis method can be applied by treating the solid plastic wastage thermally which will break the long polymeric chain structure of the plastic. This will result in the conversion of plastic into hydrocarbon fuels like jet fuel, kerosene, gasoline, auto-gas and other inflammable products which can be used in aerospace industries, general transportation sector, thermal power plants and other industrial sectors. Different types of fuels with different properties can be obtained from different grades of plastics.
\end{abstract}

Keywords: Decomposition, Hydrocarbon Fuel, Green technology, Plastic waste, Pyrolysis, Waste management.

\section{INTRODUCTION}

Over 100 million of plastic is manufactured globally. As plastic is non-biodegradable substance, it takes decades to get decomposed naturally [1]. Hence it stays in environment for a long period of time and adversely impacts environment [2]. Nearly $60 \%$ of plastic waste is recycled out of waste that is produced every day in India [3]. Also around 3500 tonnes of plastic waste was generated in 60 major cities of India in the year 2010-11 [4]. Report of American Society for testing and Materials D5033-00 states that on the basis of final products the plastic recycling process can be categorized into four types [5]. Generally, plastics are of four kind namely polypropylene, polystyrene, high density polyethylene and low density polyethylene [6]. The tertiary or chemical recycling degradation is one of the categories.

Revised Manuscript Received on February 05, 2020.

* Correspondence Author

Prafull Tiwari*, Department of Mechanical, Medi-Caps University, Indore, India. Email: prafull13tiwari@gmail.com

Kunal Jain, Department of Mechanical, Medi-Caps University, Indore, India. Email: kunalkj6656@gmail.com

Kushagra Dubey, Department of Mechanical, Medi-Caps University, Indore, India. Email: dubey.kushagra38@gmail.com

Mohammed Ali, Department of Mechanical, Medi-Caps University, Indore, India. Email: hodme@medicaps.ac.in

Manish Thakur, Department of Mechanical, Medi-Caps University, Indore, India. Email: manish.thakur@medicaps.ac.in

(c) The Authors. Published by Blue Eyes Intelligence Engineering and Sciences Publication (BEIESP). This is an open access article under the CC BY-NC-ND license (http://creativecommons.org/licenses/by-nc-nd/4.0/)
From this method of chemical degradation, liquid fuels and high value added chemicals are produced by waste plastic fragments. One of the tertiary recycling methods is pyrolysis.

\section{A. Pyrolysis}

Pyrolysis is a process of decomposing plastics by heating in absence of oxygen generating gaseous and liquids products which can be utilized as fuels. This process can be thermal or catalytic and is an alternative that allows the conversion of polymers into gas and liquid hydrocarbons. The plastic waste is processed to produce petrochemical compounds.

\section{B. Thermal Pyrolysis}

In pyrolysis, temperature ranges from $280^{\circ} \mathrm{C}$ to $350^{\circ} \mathrm{C}$ [7] and generally following products are derived.

a) Non condensable gases

b) Liquid fraction (paraffin, olefins, naphthenes and aromatics)

From liquid fraction following range products are obtained,
a) Gasoline range $\left(\mathrm{C}_{4}-\mathrm{C}_{12}\right)$
b) Diesel Range $\left(\mathrm{C}_{12}-\mathrm{C}_{23}\right)$
c) Kerosene Range $\left(\mathrm{C}_{10}-\mathrm{C}_{18}\right)$
d) Solid waste

\section{PLASTIC WASTE ANALYSIS}

\section{A. Management of commercial and household Plastic} waste:

Generally plastic waste is managed by recycling it and converting it into same or other useful products, this process also produces toxic by-products. Also plastic cannot be recycled again and again and after undergoing through few recycling processes it becomes unsuitable for recycling again and finally gets dumped onto islands or gets buried in the sea.

\section{B. Management of Marine Plastic Waste:}

Marine waste usually called as Marine Debris or Marine litters and they are generally non-repairable/out of use products of industries like shipping. Annually approximately 11,000 containers are unfortunately been lost in the sea because of storms and other issues. These wastes eventually end up getting settled on the seashore. Amount of 8.8 million metric tons of waste plastic is thrashed in the oceans annually [8]. Huge quantity of waste in high seas 'sink' areas, such as the equatorial convergence zone, are of special concern. 
In such areas, 'rafts' of mixed waste, like various plastics, ropes, fishing nets, cargo-associated wastes such as tonnage, pallets, wires and plastic covers, drums and shipping containers can be seen spreading mostly everywhere . Ship-breaking operations in India are carried out over a distance of about 10 to $12 \mathrm{~km}$ on the beaches of Alang Gujarat - one of the busiest and largest ship-breaking yards globally. When a ship is dismantled it cause release of harmful pollution causing components like Asbestos, PCB's. Components like PVC and PBB's, which are dumped into the sea directly [9]. All the recyclable plastic is sent to recycling units.

\section{Management of Tyre Waste:}

Tires comprising of vulcanized rubbers like Styrene Butadiene Rubber (SBR), Natural Rubber (NR) and Polybutadiene Rubber (PBR), steel, textile cord carbon black and small amount of other constituents. The disposal of waste tyres is one of the important issue over the environmental all over the world. More than $2.5 \times 10^{6}$ tonnes in North America, $1 \times 10^{6}$ tonnes in Japan and $3.4 \mathrm{x}$ $10^{6}$

10 tonnes of end-of-life tyres are generated annually in European Union. India has recorded over 230 million vehicles registered on its roads in the year 2016 which is third largest road network globally. Oils and gases can be synthesized via pyrolysis. Oil gained through pyrolysis have high gross calorific value (GCV) of approximately 41-44 MJ/kg. These oils can also be used to derive light aromatics such as benzene, toluene and xylene. Also active charcoal can be prepared from tires. It is observed that pyrolysis gas fraction consists of high concentrations of methane, ethane, butadiene and other hydrocarbon gases whose GCV is approximately $37 \mathrm{MJ} / \mathrm{m}^{3}$ [10].

\section{EXPERIMENT-}

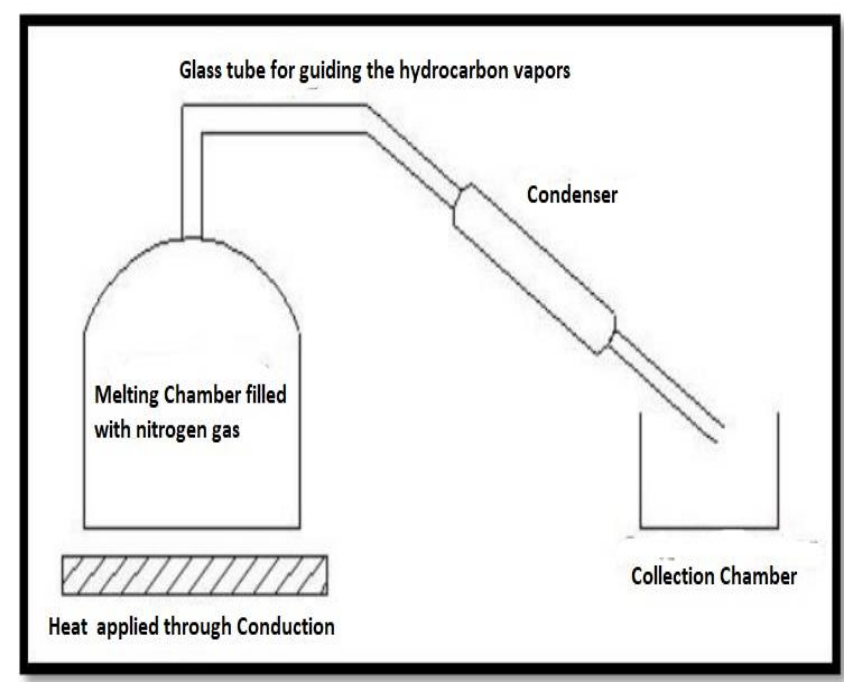

Fig 1. Block diagram of proposed model

\section{A. Condenser}

Condenser is actually a counter flow heat exchanger which helps in bringing down the temperature of the vapors coming out of the reactor that is flask. There are two openings, one for inlet and the other for outlet for inlet and outlet of cold water to run through its outer area. This is used for cooling the vapor. The gaseous hydrocarbons at a temperature of about $350^{\circ} \mathrm{C}$ are condensed to about $32-$ $35^{\circ} \mathrm{C}$. Coolant is supplied to the condenser through two pipes, one for inlet and one for outlet and both of them having length of 1 meter each.

\section{B. Melting Chamber (Three neck flask)}

Melting chamber is a three neck flask made of Borosil glass of capacity $500 \mathrm{~mL}$ with the net openings of $2.5 \mathrm{~cm}$. The whole flask is placed on top of a metallic structure which is placed on top of an induction cooker for external heating purpose. The melting chamber is heated to a temperature of about $350^{\circ} \mathrm{C}$.

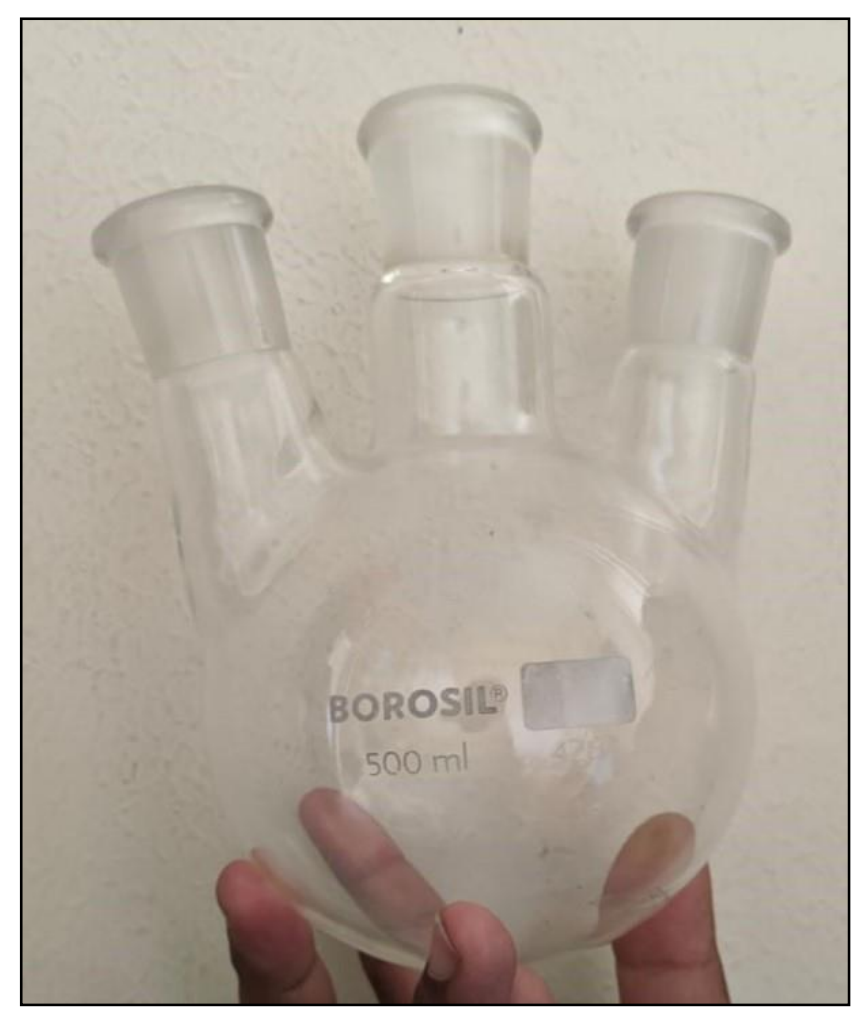

Fig 2. Three Neck Flask 500ml Capacity

\section{Heating Source}

Induction cooker with a metallic stand for resting the flask is used for heating the flask. The capacity of the induction used is 2000 Watts. Induction cooker works on the principle of eddy currents. So to heat up the plastic material, metallic structure was built on the induction surface on which the eddy currents are generated and when this metallic structure gets heated up, the heat is transferred to the melting chamber through conduction.

\section{Nitrogen Cylinder}

Nitrogen cylinder with a pressure of 140 psi and weighing around $80 \mathrm{~kg}$ is employed for supplying the nitrogen in the melting chamber. The pressure is controlled using a pressure regulator and the outlet pressure is measured by using a built in pressure gauge in the regulator. Pressure gauge used is single pressure regulator having maximum capacity of 250 $\mathrm{kg} / \mathrm{cm}^{2}$. 


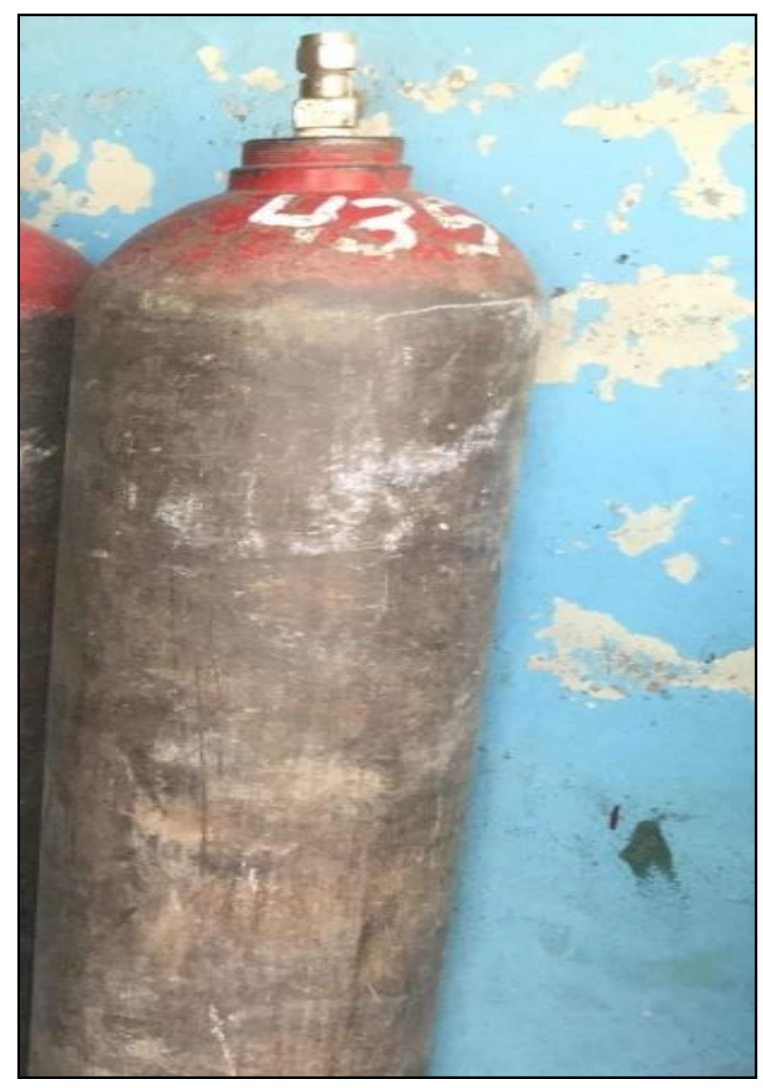

Fig 3. Nitrogen gas cylinder (140 psi pressure)

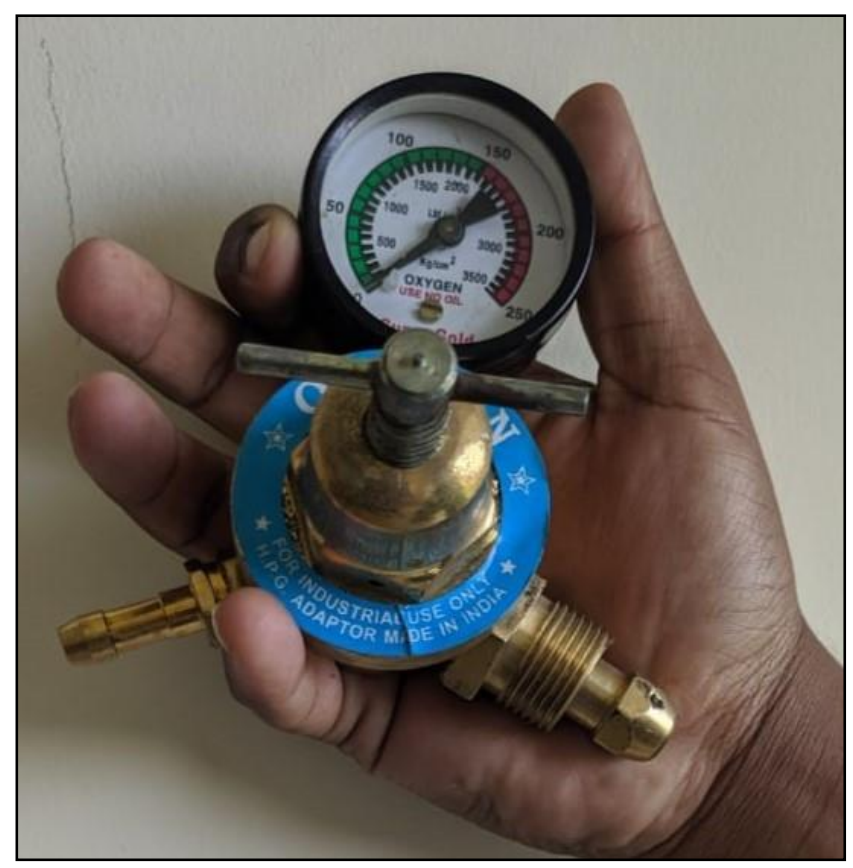

Fig 4. Pressure Regulator

\section{E. Condenser pump}

A single stage submersible water pump of 48 watts, operating at 200-220 volts and 50-60 Hz current frequency is used for the circulation of coolant in the condenser tube. The maximum discharge flow of the pump is 100-500 LPM and has a water lifting capacity of $15 \mathrm{~m}$ to $50 \mathrm{~m}$. Water at the room temperature at around $25^{\circ} \mathrm{C}$ pumped into the condenser.

\section{PROCESS DESCRIPTION}

The type of plastic utilized in the experiment is Low Density Polyethylene that is LDPE. The plastic was collected from the medical packaging waste. The plastic scrap is thoroughly washed to remove any dirt or any other solid impurities. Solid waste plastic is melted in absence of oxygen and this method is called thermal cracking. The scrap was trimmed into pieces of size ranging from $1.5-2 \mathrm{~cm}$ as was spread on the bed of the melting chamber for uniform heating. In this experiment around $2 \mathrm{~kg}$ of LDPE will be utilized to gain different samples. Each batch will be synthesized from 200 gm. of LDPE at a time. The melting process is carried out in an inert atmosphere by displacing the oxygen inside the flask with nitrogen. A low density poly-ethylene plastic is used in a batch system as changes of temperature difference for these plastics are relatively low. Initially the plastic scrap is subjected to a temperature of $100{ }^{\circ} \mathrm{C}$ a liquid slurry is obtained as the temperature increases. At about $265^{\circ} \mathrm{C}$ this slurry gets turned into hydrocarbon vapors. These vapors are then allowed to pass through a counter flow condenser which brings down the temperature of the vapor and at the end the condensed vapors or say synthetic fuel are collected into a beaker. Around $20-30 \%$ of the fuel is collected between $100^{\circ} \mathrm{C}$ and $250^{\circ} \mathrm{C}$. The next $40 \%$ is collected when the temperature is raised to around $310^{\circ} \mathrm{C}$ and the experiment is stopped when the temperature reaches up to $350^{\circ} \mathrm{C}$ and the final yield is obtained. As the plastic contains hydrocarbon from short chain hydrocarbon to long chain hydrocarbon so the plastic's structure do not break immediately during the thermal cracking. Initially the short chain hydrocarbons start breaking from the temperature of $200^{\circ} \mathrm{C}$. When temperature profile is increased the plastic carbon-carbon bond breakdown slowly. As the temperature is increased the long chains are breakdown step by step. During in this thermal cracking process some light gas such as methane, ethane, propane and butane are produced. These compounds are not able to condense because they have negative boiling point. These light gases could be alkane or alkene group and it can also contain $\mathrm{CO}$ or $\mathrm{CO}_{2}$ emissions. This gas portion analysis is under consideration. The method which is considered for treating the light gas is an alkali wash system. After experiment is concluded some solid black residue is left in the melting chamber. To purify the liquid fuel a purification system to remove water portion and ash or fuel sediment is used and it is also filtered with filter paper to remove some solid waste mixed in fuel while collecting in bottle. Overall five batches of synthetic fuel were produced.

The following apparatus or methods were used to find out the properties of the liquid fuel obtained:

a) Pensky Martin apparatus was utilized for measuring the flash point and fire point of the synthetic fuel.

b)Bomb calorimeter was utilized to measure the gross calorific value of the fuel.

c) Saybolt viscometer and Rosewood viscometer apparatus were utilized to measure kinematic and absolute viscosity.

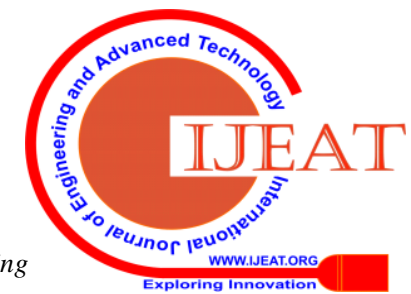


d)The density was calculated by dividing the observed mass of the obtained by the observed volume (values provided in table-I).

\section{RESULTS AND DISCUSSION-}

Physical manifestation of the synthetic fuel obtained through the pyrolysis setup is like a viscous fluid having dim-yellowish color appearance and a foul odor. The synthetic liquid obtained is highly flammable furthermore it burns completely without any left-over residue. $200 \mathrm{mg}$ of plastic was used to produce a single batch of the synthetic fuel sample and the corresponding values of liquid composition, gaseous composition and solid residue composition obtained at the end of the complete process can be found in the Table-I. Around $155 \mathrm{gm}$. of liquid fuel was synthesized from $200 \mathrm{gm}$. of LDPE plastic. Five batches of the sample were produced and these samples were tested for various properties such as density, specific gravity, calorific value, flash point, fire point, kinematic viscosity and absolute viscosity. The outcomes found during testing of the synthetic fuel sample obtained in the experiment are mentioned in the Table-II and it can be observed that the specific gravity and density of the synthetic fuel will be more than those of petrol and less than that of diesel. From the values given in the Table-II it should be obvious that kinematic viscosity and dynamic viscosity of synthetic fuel is more than that of petrol and less than that of diesel. The flash point and fire point of synthetic fuel is more than the petrol and less than the diesel is observed. The gross calorific value of synthetic fuel is less than that of petrol and more than that of diesel.

Table i: synthetic fuel composition synthesized from $200 \mathrm{gm}$. Of plastic waste

\begin{tabular}{|c|c|c|}
\hline & \multicolumn{2}{|c|}{ Composition } \\
\hline & Weight & Percentage \\
\hline $\begin{array}{l}\text { Liquid Composition } \\
\text { (Synthetic fuel) }\end{array}$ & $\begin{array}{l}155 \text { gm. (201 } \\
\text { ml.) }\end{array}$ & 77.5 \\
\hline Solid Residue & 15 gm. & 7.5 \\
\hline $\begin{array}{c}\text { Gaseous } \\
\text { Composition }\end{array}$ & 30 gm. & 15 \\
\hline
\end{tabular}

TABLE II: Properties Of Fuels

\begin{tabular}{|c|c|c|c|}
\hline \multirow[t]{2}{*}{ Properties } & \multicolumn{3}{|c|}{ Fuel Type } \\
\hline & Petrol & Diesel & $\begin{array}{l}\text { Synthetic } \\
\text { Fuel }\end{array}$ \\
\hline \multirow{7}{*}{$\begin{array}{l}\text { Density } \\
\left(\mathrm{Kg} / \mathrm{m}^{3}\right) \\
\text { Specific } \\
\text { Gravity } \\
\text { Flash point } \\
\text { (Celsius) } \\
\text { Fire point } \\
\text { (Celsius) } \\
\text { Absolute } \\
\text { Viscosity } \\
\text { Kinematic } \\
\text { Viscosity } \\
\text { Calorific } \\
\text { Value (KJ/Kg) }\end{array}$} & 742 & 850 & 771 \\
\hline & 0.742 & 0.850 & 0.771 \\
\hline & 23 & 50 & 30 \\
\hline & 29 & 56 & 36 \\
\hline & 2.42 & 3.05 & 2.62 \\
\hline & 1.79 & 2.59 & 2.01 \\
\hline & 46858 & 42000 & 42680 \\
\hline
\end{tabular}

Fig 5. Kinetic Viscosity and Dynamic Viscosity Note*: Kinematic viscosity is in centistokes Dynamic viscosity is in centipoise

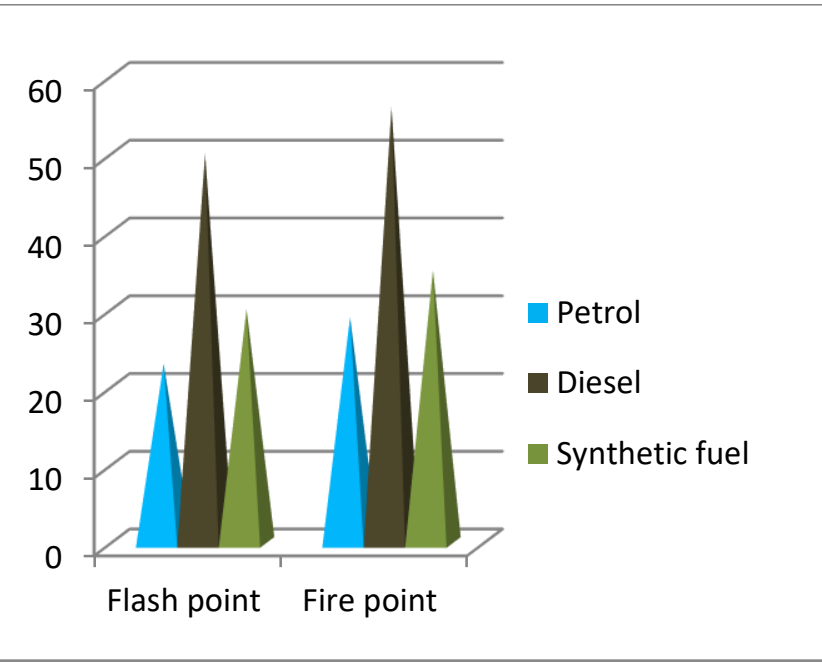

Fig 6. Flash Point and Fire Point

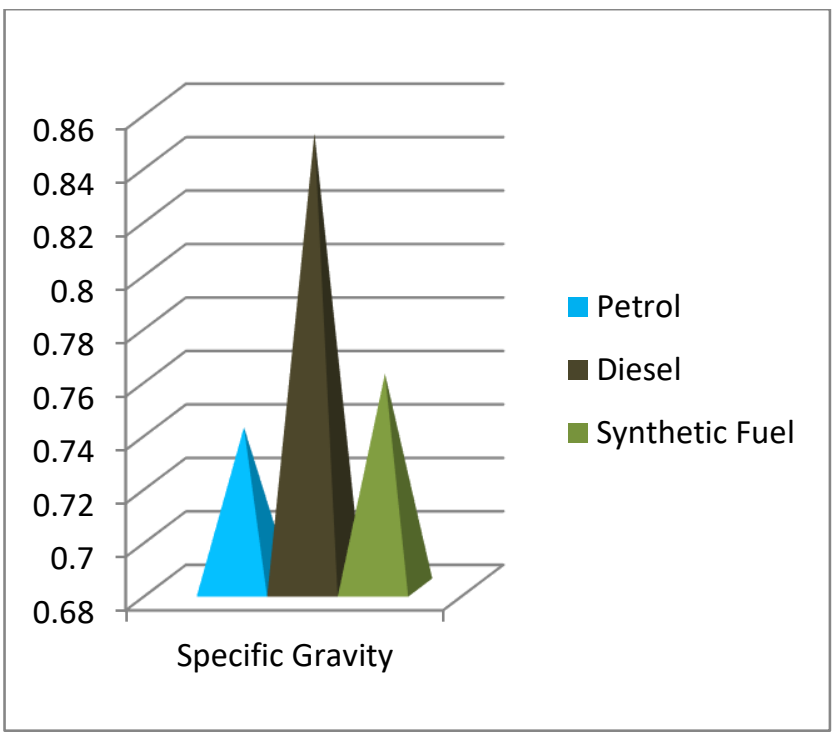

Fig 7. Specific Gravity 


\section{CONCLUSION}

From the results obtained from the experiment, it may be concluded that synthetic fuel obtained from the pyrolysis method can be a good alternative for diesel and petrol in internal combustion engines. Plastics present a major threat to today's society and environment. Over 14 million tons of plastics are dumped into the oceans annually, killing about $1,000,000$ s of aquatic life. The conversion of this solid waste plastic to fuel will spare the aggregation of plastic on the sea beds. The hydrocarbon fuel that has been produced by the LDPE plastic by the pyrolysis process shows the properties that are very much comparable to the petrol. Ultimately, pyrolysis of LDPE does not only recover the energy contained in the plastic, but also manage the environment by alternate disposal technique of the waste plastic. This process can lead to a sustainable, clean and green future. By taking under record the budgetary profits of such a project, it might propose an incredible help the economy.

\section{REFERENCES}

1. Santosh U Kumar, Ketan Nalawade, Anil Jadhav\&T. VijayKumar, "Extraction of Plastic Oil from Plastic Oil from Plastic by DePolymerization Technique as an Alternative Fuel". International Journal of Applied Engineering \&Research (2013).

2. Pawar Harshal R. and Lawankar Shailendra M., "Waste Plastic Pyrolysis Oil Alternative Fuel for CI Engine”, A Review Research Journal of Engineering Sciences ISSN2278 - 9472Vol. 2(2), 26-30, February (2013).

3. Dr. P.V. Thorata, Miss. Sandhya Warulkara, Miss.Harshal Sathonea, "Thermo fuel Pyrolysis of Waste Plastic to Produce Liquid Hydrocarbons", Advances in Polymer Science and Technology: An International Journal ISSN2277 - 7164

4. "STATUS OF IMPLEMENTATION OF PLASTIC WASTE MANAGEMENT," Government of India, 2015.

5. OCEAN RECOVERY ALLIANCE, "2015 PLASTICS-TO-FUEL PROJECT DEVELOPER'S GUIDE," Hong Kong, 2015

6. Roopa Farshi, Chirayu Belthur, Anjan Athreyas \& George Jeevan, Ramesh, "Catalytic Degradation Of Municipal Waste Plastics To Produce Fuel Range Hydrocarbons Using Bentonnite”. Department of Chemical Engineering DSCE, Bangalore. International Journal of Current Engineering \& Technology (2013).

7. D. Almeida and M. d. F. Marques, "Thermal and catalytic pyrolysis of plastic waste".

8. L. Jeftic, S. Sheavly, E. Adler and N. Meith, "Marine Litter: A global Challenge," UNITED NATIONS ENVIRONMENT PROGRAMME, Nairobi, 2009.

9. R. Kumar, "SHIP DISMANTLING: A Status Report in South Asia," Euro consult Mott MacDonald and WWF-India

10. P. M. Bhatt and P. Patel, "SUITABILITY OF TYRE PYROLYSIS OIL (TPO) AS AN ALTERNATIVE FUEL FOR INTERNAL COMBUSTION ENGINE," International Journal of Advanced Engineering Research and Studies, vol. 1, no. 4, pp. 61-65, 2012.

\section{AUTHORS PROFILE}

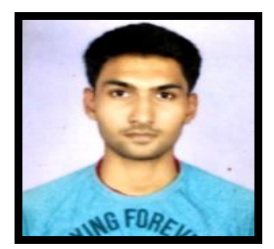

Mr. Prafull Tiwari currently pursuing B.Tech (Mechanical 2016-2020) at Medi-Caps University, Indore (MP) India.

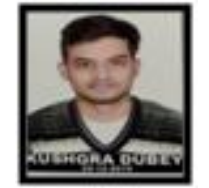

Mr. Kushagra Dubey currently pursuing B.Tech (Mechanical 2016-2020) at Medi-Caps University, Indore (MP) India.

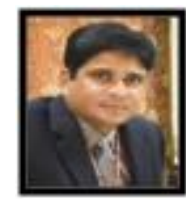

Dr. Mohammed Ali B.E. (Mechanical), M.Tech (Mechanical), PhD (Mechanical) Professor and Head of the Department Mechanical Engineering Department, Medi-Caps University, Indore (MP) India.

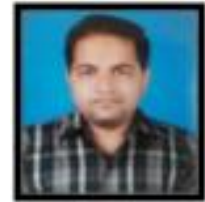

Prof. Manish Thakur currently working as associate professor in mechanical engineering department at Medi-Caps University. He has done his M.E. from BM College of Technology, (PRODUCTION AND MACHINE DESIGN) and B.E. from Pt. R.S.S. University Raipur.

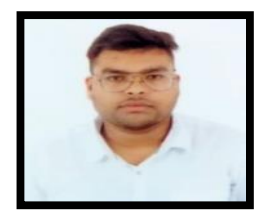

Mr. Kunal Jain currently pursuing B.Tech (Mechanical 2016-2020) at Medi-Caps University, Indore (MP) India. 